\title{
РОЗРОБКА ІМІТАЦІЙНОї МОДЕЛІ ГІДРОСИСТЕМИ УПРАВЛІННЯ СТОПОРОМ ПРОМКОВША МБЛЗ
}

\author{
Чернишев М.М. ${ }^{1}$ \\ ${ }^{1}$ ДВНЗ «Донецький національний технічний університет», м. Донецьк \\ Email: kolyachernishov@mail.ru
}

Copyright (C) 2014 by author and the journal “Automation technological and business - processes”. This work is licensed under the Creative Commons Attribution International License (CC BY). http://creativecommons.org/licenses/by/4.0/

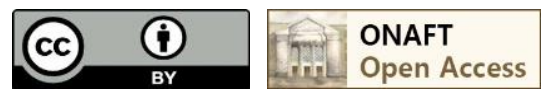

\begin{abstract}
Анотація
В статті розглянута імітаційна модель гідравлічної системи стопорного дозуючого пристрою машини безперервного лиття заготовки.
\end{abstract}

Abstract

The simulation model of hydraulic system for continuous casting machine mold with stopper dosing mechanism is considered in this paper.

Ключові слова

Імітаційна модель, гідравлічна система, стопор, МБЛЗ.

Постановка проблеми

Машини безперервного лиття заготовки (МБЛЗ) є одним з головних елементів сучасного сталеплавильного цеху. Ефективність безперервного розливання як технологічного процесу, багато в чому сприяла розвитку чорної металургії в цілому. Регулювання рівня металу в кристалізаторі має першорядне значення для процесу безперервного розливання, тому що якість злитків у більшій мірі залежить від точності регулювання. Рівень у процесі розливання повинен перебувати в досить вузьких заданих межах, що обумовлено наступними причинами $[1,2,3]$ :

- перевищення рівня може привести до переливу металу через верх кристалізатора;

- зниження рівня нижче припустимої межі приводить до одержання в межах кристалізатора тонкої скоринки злитка, яка може розірватися під кристалізатором.

На практиці найбільше поширення отримав метод дозування сталі за допомогою стопорного механізму [3,4]. Стопорний механізм лінійно переміщається щодо стакану-дозатора та змінює витрату металу в кристалізатор 3 проміжного ковша. Гідросистема управління стопорами призначена для керування роботою стопорів в режимі АСУТП [5]. Ця система повинна мати високу швидкодію та забезпечувати точність переміщення стопора. Тому актуальною задачею $є$ розробка математичної моделі системи електрокерування гідросистеми управління стопором промковша МБЛЗ з урахуванням реальних фізичних параметрів системи.

Мета: Розробка імітаційної моделі гідросистеми управління стопором для дослідження поведінки системи в різноманітних режимах роботи. 


\section{2 АВТОМАТИЧНІ І АВТОМАТИЗОВАНІ СИСТЕМИ УПРАВЛІННЯ ТЕХНОЛОГІЧНИМИ ПРОЦЕСАМИ}

Задачі:

1. Визначити кінематичну схему та принцип роботи системи управління переміщенням стопора.

2. Розробити модель гідросистеми управління стопором використовуючи реальні технічні характеристики та склад обладнання.

Кінематична схема та принцип роботи системи управління переміщенням стопора

На промковш (1) встановлюється механізм підняття стопорів для кожного струмка (рис. 1). Стопорний механізм складається зі стопора (2), важеля (3), направляючої труби (4), гідравлічного (5) приводу та гідророзподілювача (6).

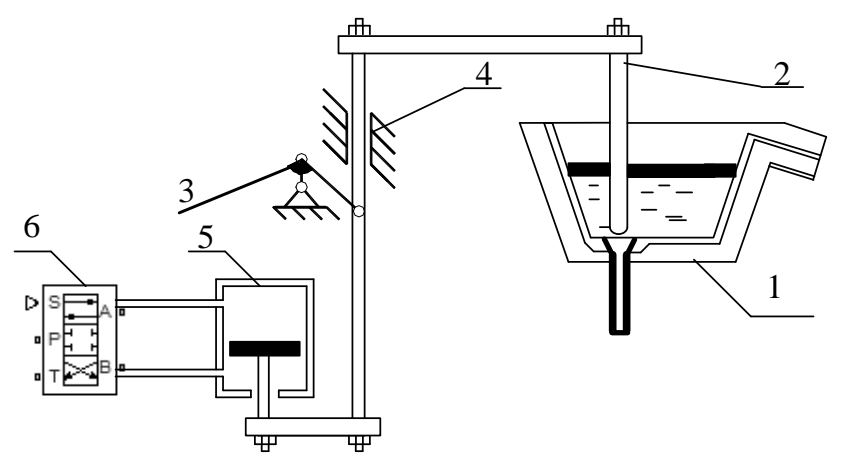

Рис. 1. Схема механізму переміщення стопора

При зміні рівня металу в кристалізаторі автоматично здійснюється переміщення стопору гідроциліндром в необхідному напрямку. Оскільки стопор жорстко пов'язаний з гідроциліндром, то стан стопора повторює положення штока в гідроциліндрі. В свою чергу, переміщенням штока гідроціліндра керують сервоклапани. На сервоклапани подається сигнал 3 контролера, що визначає необхідне значення переміщення штока гідроциліндра [6,7].

Принцип роботи гідросистема полягає у наступному. Робоча рідина від насосно-акумуляторної станції сталерозливного стенду через відкритий кран надходить до блоку фільтрів під тиском 20 МПа. Після проходження блоку фільтрів, робоча рідина надходить у редукційний клапан, де тиск знижується до 10 МПа $\mathrm{i}$ акумулюється в гідро-пневмоакумуляторі. У гідрошафах зосереджена розподільна, регулююча, фільтруюча гідроапаратура, що забезпечує виконання команд електрокерування в «ручному» і «автоматичному» режимах управління.

Розробка моделі гідросистеми управління

Для розробки імітаційної моделі використано програму Simscape, що використовує підхід каузального моделювання. При побудові моделі: компоненти, що відносяться до фізичних елементам, таким, як насоси, двигуни та клапани, з'єднуються лініями, що представляють фізичні з'єднання, по яких передається енергія. Simscape служить основою для моделювання в Simulink електросилових, механічних і гідравлічних об'єктів. Бібліотека розширюється спеціалізованими пакетами SimMechanics, SimDriveline, SimHydraulics i дозволяє будувати моделі складних об'єктів для різних задач аналізу, в тому числі для розробки цифрових систем управління $[8,9,10]$.

На рис. 2 представлена моделі гідросистеми управління стопором.

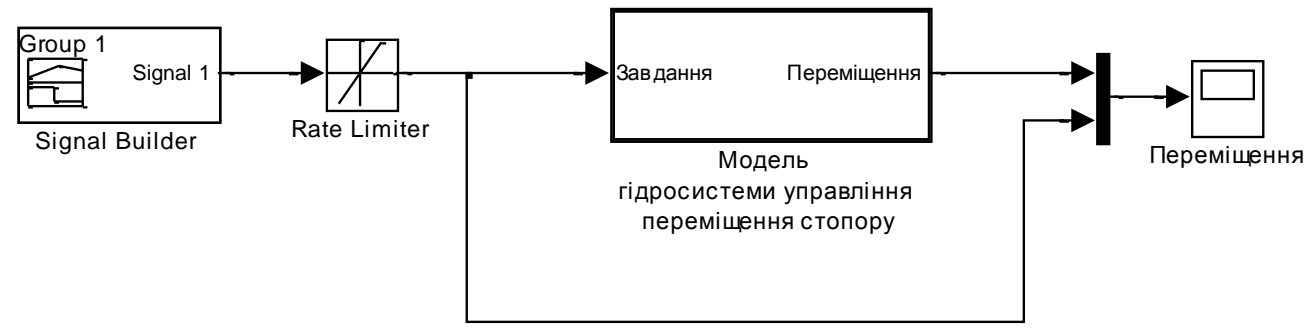




\section{$\underline{2}$ АВТОМАТИЧНІ І АВТОМАТИЗОВАНІ СИСТЕМИ УПРАВЛІННЯ ТЕХНОЛОГІЧНИМИ ПРОЦЕСАМИ}

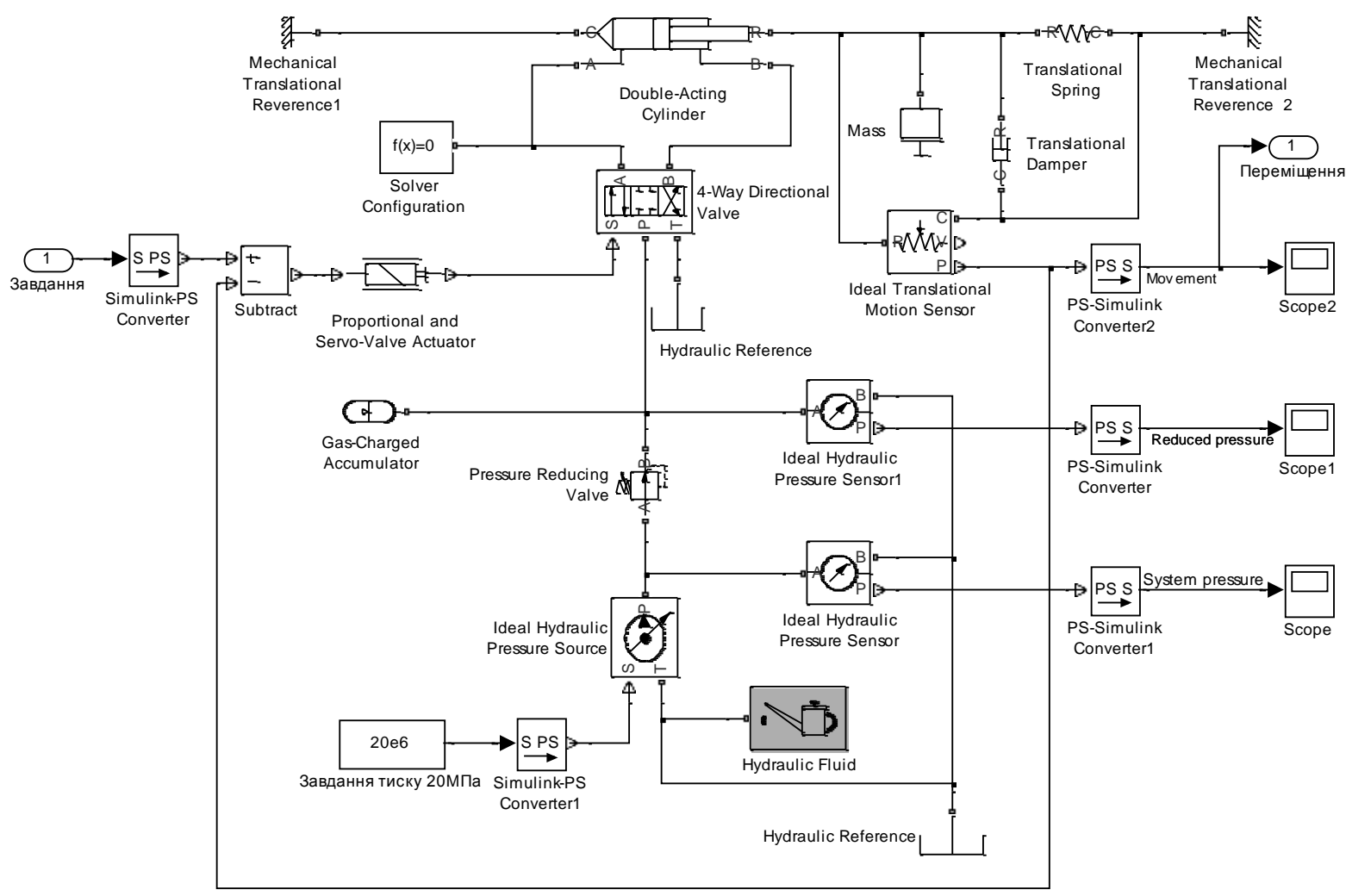

Рис. 2. Імітаційна модель гідросистеми переміщення стопора

До складу моделі входять:

1. Джерело тиску «Ideal Hydraulic Pressure Source». Блок має два «гідравлічних» порту і один порт для керуючого сигналу, який, власне і визначає тиск, що буде відправлено до лінії Р, щодо лінії Т. Однак, вхід для керуючого сигналу необхідно перетворити у «фізичний» сигнал за допомогою конвертеру «Simulink-PS Converter»;

2. Блок рідини «Нydraulic Fluid» дозволяє задати параметри рідини, що використовується в системі;

3. Редукційний клапан «Pressure Reducing Valve» знижує тиск до потрібного значення;

4. Гідро-пневмоакумулятор «Gas-Charged Accumulator» наколює енергію та віддає іiі при зниженні тиску нижче критичного рівня;

5. Розподільник 4/3 із закритим центром «4-Way Directional Valve». Блок має наступні порти:

-Р «гідравлічний» порт, що пов'язаний з входом лінії подачі тиску;

-Т «гідравлічний» порт, що пов'язаний з підключенням до зворотної лінії;

-А «гідравлічний» порт, що пов'язаний з портом з'єднання гідроциліндру;

-В «гідравлічний» порт, що пов'язаний з портом з'єднання гідроциліндру;

-S «фізичний» порт, що пов'язаний з сигналом для управління розподільником.

6. Пропорційний сервопривід клапану розподільника «Proportional and Servo-Valve Actuator», дозволяє імітувати безперервний драйвер клапану з вихідним сигналом, пропорційний вхідному сигналу;

7. Гідравлічний циліндр подвійної дії «Double-Acting Hydraulic Cylinder» імітує гідравлічний привід, що рухається в двох напрямках. Він перетворює гідравлічну енергію в механічну енергію у формі поступального руху. Блок має наступні порти:

-А «гідравлічний» порт, що пов'язаний з портом А розподільника;

-В «гідравлічний» порт, що пов'язаний з портом В розподільника;

-R «механічний» порт, що пов'язаний зі штоком циліндра;

-C «механічний» порт, що пов'язаний з системою запирання циліндру.

8. Стопорний механізм, що моделюється наступними блоками:

-блок «Mass», симулює масу у механічних системах;

-блок «Translational Damper», симулює демпфування в механічних системах; 


\section{$\underline{2}$ АВТОМАТИЧНІ І АВТОМАТИЗОВАНІ СИСТЕМИ УПРАВЛІННЯ ТЕХНОЛОГІЧНИМИ ПРОЦЕСАМИ}

-блок «Translational Spring», симулює жорсткість в механічних системах;

-блок «Mechanical Translational Reverence», симулює контрольну точку, або рамку для механічних перевідних портів.

9. Датчики:

-датчик поступального руху «Ideal Translational Motion Sensor». Блок має наступні порти:

-R «механічний» порт, що пов'язаний з позитивним входом датчика;

-C «механічний» порт, що пов'язаний з негативним входом датчика;

-V «фізичний» сигнал для швидкості;

-Р «фізичний» сигнал для позиції.

-датчик гідравлічного тиску «Hydraulic Pressure Sensor». Блок має наступні порти:

-А «гідравлічний» порт, що пов'язаний з позитивним входом датчика;

-В «гідравлічний» порт, що пов'язаний з негативним входом датчика;

-Р «фізичний» сигнал, який виводить значення тиску.

10. Суматор «Substact», що виконує порівняння заданого переміщення з поточним;

11. Блок «Solver Configuration» визначає інформацію для моделювання з усіх блоків, що використовують «фізичні» сигнали та задає параметри для вирішення задачі моделювання;

12. Блок «Signal Builder» дозволяє згенерувати сигнал, що задає вид сигналу необхідного переміщення стопору (рис. 3).

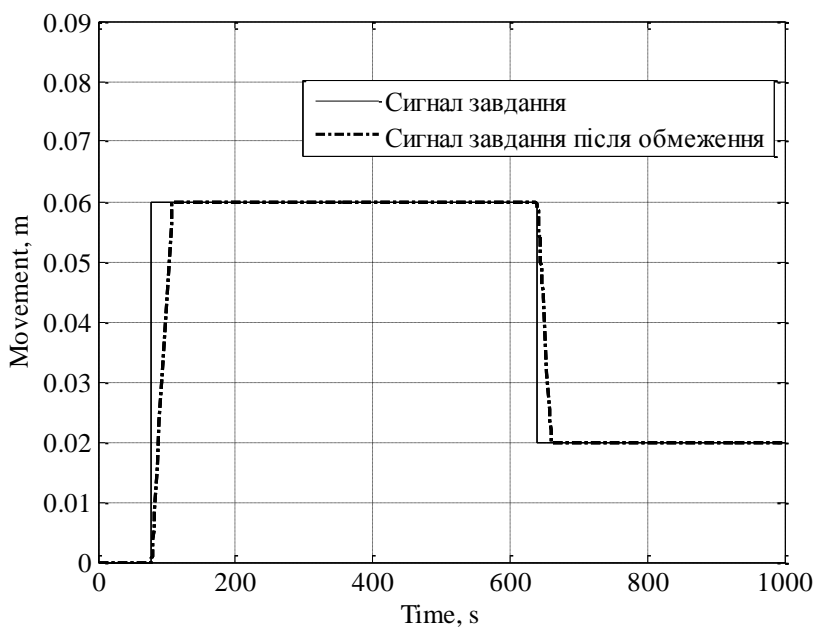

Рис. 3. Графік зміни сигналу завдання на переміщення стопору

13. Для обмеження швидкості руху штока гідроциліндру до 2 мм/с використано блок «Rate Limiter» (рис. 3).

14. Блок «Sсоре» дозволяє спостерігати за змінами сигналів в процесі моделювання.

Таким чином, моделювання динамічних процесів у гідравлічних системах засобами Simulink та Simscape $є$ набагато простішим для сприйняття. Все полягає у правильному складанні принципової схеми відповідно до складу та технічних параметрів гідросистеми.

Графіки отриманих результатів моделювання гідросистеми управління переміщення стопору під час відпрацювання сигналу завдання наведено на рисунку 4.

\section{Висновки}

1. Визначена кінематична схема та принцип роботи системи управління переміщенням стопора, що використовується при безперервній розливці сталі;

2. Побудовано модель імітації руху роботи гідросистеми переміщення стопора засобами Matlab\&Simulink та Simscape, що дають можливість для подальшого розв'язування різноманітних задач динаміки;

3. Використовуючи наведений у статті спосіб дослідження динамічних характеристик гідравлічних та механічних систем дозволить в короткій терміни проводити моделювання процесів в різноманітних режимах роботи. 


\section{$\underline{2}$ АВТОМАТИЧНІ І АВТОМАТИЗОВАНІ СИСТЕМИ УПРАВЛІННЯ ТЕХНОЛОГІЧНИМИ ПРОЦЕСАМИ}

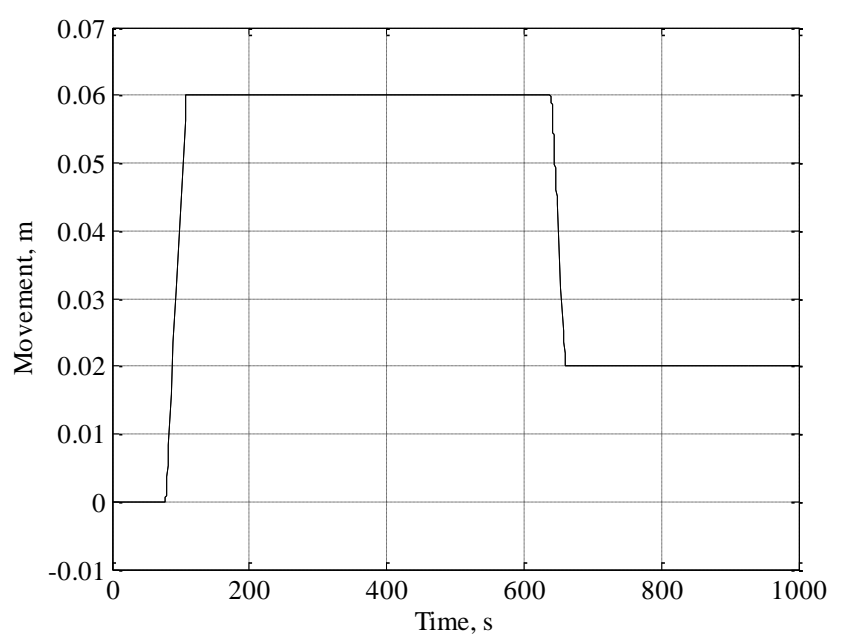

Рис. 4. Перехідний процес зміни положення стопору промковша МБЛЗ

3 отриманих результатів (рис. 3 та 4) можна зробити висновок, що переміщення стопору співпадає 3 бажаним.

\section{Література}

1. Цупрун А.Ю. Системы управления процессами и механизмами машин непрерывного литья заготовок / А.Ю. Цупрун, А.Г. Редько, А.В. Колоколов, Д.А. Онух, В.М. Пильгаев // Украинская Ассоциация Сталеплавильщиков. - Режим доступа: http://uas.su/conferences/2010/50let/32/00032.php;

2. Смирнов А.Н. Непрерывная разливка стали / А.Н. Смирнов, С.В. Куберский, Е.В. Штепан. - Донецк: ДонНТУ, 2011. - 482 c;

3. SIMETAL LevCon. Mold level control and stability with the utmost precision. - Режим доступа: http://www.industry.siemens.com/datapool/industry/industrysolutions/metals/simetal/en/SIMETAL-LevConen.pdf;

4. Дюдкин Д.А., Кисиленко В.В., Смирнов А.Н. Производство стали. Том 4. Непрерывная разливка металла. - М.: «Теплотехника».- 2009. - 528 с;

5. Чернышев Н.Н. Модернизированная система автоматического регулирования уровнем металла в кристаллизаторе МНЛЗ / Н.Н. Чернышев, О.С. Волуева // Сучасні тенденції розвитку інформаційних технологій в науці, освіті та економіці : матеріали VIII Всеукр. наук.-практ. конф. (м. Луганськ, 17 18 березня 2014 р.). - Луганськ : Вид-во ДЗ „ЛНУ імені Тараса Шевченка”, 2014. - С. 122-124;

6. Чернышев Н.Н. Комбинированная система автоматического регулирования уровнем металла в кристаллизаторе / Н.Н. Чернышев // Наукові праці Донецького національного технічного університету. Сер. обчислювальна техніка та автоматизація, випуск 2(25). - Донецьк: ДонНТУ. - 2013, С. 72-78;

7. Волуева О.С. Система регулирования положения стопорной системы промковша машины непрерывного литья заготовок. Науковий вісник Чернівецького національного університету імені Юрія Федьковича. Серія: Комп’ютерні системи та компоненти. - Том. 3, випуск 2. - Чернівці: ЧНУ. - с.7478 ;

8. Simscape. Моделирование и симуляция многодисциплинарных физических систем. - Режим доступа: http://matlab.ru/products/simscape/Simscape-rus.pdf;

9. SimHydraulics. Моделирование и симуляция гидравлических систем. - Режим доступа:http://matlab.ru/products/simhydraulics/simhydraulics_rus_web.pdf;

10. SimMechanics. Симуляция и моделирование многотельных механических систем. - Режим доступа:http://matlab.ru/products/simmechanics/simmechanics_rus_web.pdf. 